\title{
The recommendations of the Brazilian College of Surgeons and the Brazilian Bariatric and Metabolic Surgery Societies on the return of bariatric and metabolic operations in geographic regions of the country where the procedures have been allowed by local policies, in the period of COVID-19 pandemic
}

\author{
Recomendações do Colégio Brasileiro de Cirurgiões e da Sociedade Brasileira \\ de Cirurgia Bariátrica e Metabólica para o retorno às cirurgias bariátricas e \\ metabólicas em regiões epidemiológicas flexibilizadas, no período de pandemia \\ COVID-19
}

Leonardo Emillo da Silva, TCBC-GO1,2 [i]; Ricardo Vitor Cohen, TCBC-SP3; James Camara de-Andrade, TCBC-MS4; Thomas Szegö, TCBC-SP5; Marco Aurélio Santo, TCBC-SP6; Almino Cardoso Ramos, TCBC-SP7; Marcos leão Vilas-Boas ${ }^{8}$; Cristiane Moulin Moraes-Zenóbio9; Annelise Mota Alencar-Meneguesso ${ }^{10}$; Luiz Carlos Von-Bahten, TCBC-PR ${ }^{11}$.

\begin{abstract}
A B S T R A C T
Prioritizing surgical procedures aims at facilitating patient's access according to the clinical needs, maximizing access equity, and minimizing the damage from delayed access. Previous categorization of elective bariatric surgery have been adapted to define an objective prioritizing system that reflects those principles for bariatric and metabolic operations. Given the factors that contribute to the morbidity and mortality of obese and type 2 diabetes patients, surgical prioritization should be based on clinical risk stratification. For patients with type 2 diabetes, we suggest that the operation may be prioritized for those with a higher risk of morbidity and mortality in a relatively short term. Likewise, it is necessary to guide the surgical team regarding the necessary care both in the pre, per and postoperative periods of bariatric and metabolic surgery. These recommendations aim to reduce the risk of in-hospital contamination of the surgical team among health professionals and between health professionals and patients. In summary, these recommendations have been shaped after a thorough analysis of the available literature and are extremely important to mitigate the harm related to the clinical complications of obesity and its comorbidities while keeping healthcare providers' and patients' safety.
\end{abstract}

Keywords: Bariatric Surgery. Diabetes Mellitus, Type 2. Obesity. Comorbidity. Coronavirus. Pandemics.

\section{INTRODUCTION}

\begin{abstract}
S COVID-19 pandemic presents different Abehaviors according to the various regions while the adherence of the population to social distancing and hygiene measures have been positive, there are increasing questions regarding the right moment to
\end{abstract}

resume elective surgical procedures. The latter have been canceled based on the recommendations of the main surgical scientific societies in the country.

On April 2, 2020, the Federal Council of Medicine (CFM) issued recommendations to the Regional Councils of Medicine (CRMs) to assess the need for deferring elective care (consultations, procedures,

\footnotetext{
1 - Bariatric and Metabolic Surgery Board of The Brazilian College of Surgeons - Rio de Janeiro - RJ - Brazil 2 - Federal University of Goias, Medical School - Department of Surgery - Goiania - GO - Brazil 3 - The Center for the Treatment of Obesity and Diabetes - Oswaldo Cruz Hospital, Sao Paulo - São Paulo - SP - Brazil 4 - Brazilian Society of Bariatric and Metabolic Surgery, Capitulo Mato Grosso do Sul - Campo Grande - MS - Brazil 5 - Center for Obesity and Gastroenterology Surgery - São Paulo - SP - Brazil 6 - University of São Paulo, Faculty of Medicine, Discipline of Surgery of the Digestive System - São Paulo - SP - Brazil 7 - Clínica Gastro Obeso Center - São Paulo - SP - Brazil 8 - Brazilian Society of Bariatric and Metabolic Surgery - São Paulo - SP - Brazil 9 - Regional da Asa Norte Hospital (HRAN) - Specialized Center on Diabetes, Obesity and Hypertension - Brasilia - DF - Brazil 10 - Medical Sciences College (Unifacisa) - Campina Grande - PB - Brazil 11 - The Brazilian College of Surgeons - Rio de Janeiro - RJ - Brazil
} 
and surgeries) in their jurisdictions during the COVID-19 pandemic. For this reason, the CFM has directed the legal determinations made by local authorities (Governors and Mayors), based on the current health recommendations, the capacity of the local healthcare network (public and private), and the epidemiological indicators ${ }^{1}$.

\section{BENEFITS OF BARIATRIC AND} METABOLIC SURGERIES

The Epidemiological Bulletin, edited by the Health Surveillance Secretariat of the Ministry of Health - Center for Emergency Operations in Public Health I COE-COVID-19 published on April 26, 2020, highlights the existence, in Brazil, of multiple scenarios and realities in the field of care, resulting from the nonuniform aspect of the spread of COVID-19 disease, given the country's vast territorial extent. In the same bulletin, among the confirmed deaths secondary to COVID-19, $40 \%$ of the patients had diabetes, and for all risk groups, most individuals were 60 years or older, except for those with obesity².

Several levels 1 and 2 of evidence have demonstrated that bariatric and metabolic operations are safe and, when compared to any other therapeutic strategy, and lead to a more significant and durable weight loss. Besides, there is a decrease in cardiovascular risk and mortality independently of any cause, with follow-up time greater than 20 years.

Regarding type 2 diabetes (T2D), several randomized controlled and prospective studies with thousands of patients, in a 5-year follow-up, have proved that surgery delivers better metabolic control when compared to the clinical treatment alone. Apart from this, also in studies of levels 1 and 2 of scientific evidence, metabolic surgery is superior to clinical treatment concerning T2D kidney disease ${ }^{3-9}$.

Due to the non-uniformity of how to resume elective surgeries in our country, in this transition period, it is essential to define a series of measures aimed at ensuring the maximum safety for health professionals and patients on how to return to the so-called "new normal" in the coping period of COVID-19.

1. All surgical schedules should be reviewed concerning risks, priorities, and resources according to the determination of the Regional Councils of Medicine, according to the regional/local legal determinations.

After the local governmental permission, the proper timing to resume bariatric and metabolic operations is of responsibility of the hospital technical directors ${ }^{10}$ :

a. Thus, the recommendations were classified with regards to the safe return of elective procedures:

I. Recommendations for the preoperative period.

- The period between the first consultation and the operation itself.

II. Recommendations for the perioperative period.

- The period between hospital admission and discharge.

III. Recommendations for the postoperative period.

- The period after hospital discharge.

1. Recommendations for the preoperative period.

a. The recommendations regarding the indications for surgical treatment of obesity and T2D are unchanged in relation to the CFM resolutions $n^{\circ} 2.131 / 2015$ and CFM n' 2.172/2017;

b. ANVISA, in its technical note GVIMS/ GGTES/ANVISA n 06/20, classifies elective surgeries as essential and non-essential. Essential elective operations are those for which delaying the intervention may cause harm to the patient's health, as endorgan damage may increase morbidity and mortality while waiting. Essential elective operations were defined as those that should be performed within three to eight weeks after the patient's preoperative work-up:

I. Similarly, to cancer patients, for whom there are situations that the delay of the interventions can considerably 
aggravate the clinical evolution, while decreasing the benefits related to the metabolic and bariatric procedures, ought to be considered essential elective surgeries.

c. Due to the moment of exception that the pandemic has determined, the criteria for prioritizing the candidates for bariatric and metabolic surgery should contemplate ${ }^{11}$ :

I. Regarding obesity:

- Patients with severe obesity, defined as superobese with $\mathrm{BMI}>50 \mathrm{~kg} / \mathrm{m} 2$.

- Patients with $\mathrm{BMI}>35 \mathrm{Kg} / \mathrm{m} 2$ :

a. With $>2$ comorbidities and/or,

b. Hypoventilation syndrome and/or,

c. Sleep apnea and/or,

d. End-stage renal disease and/or,

e. Congestive heart failure due to obesity and/or,

f. Prior to organ transplantation, considering that weight loss decreases the chance of severe complications and mortality.

II. Regarding type 2 diabetes:

- Patients with $\mathrm{IMC}>30 \mathrm{~kg} / \mathrm{m} 2$ :

a. HbA1c > $8 \%$ with two or more oral medications and/or,

b. Use of insulin and/or,

c. Previous history of cardiovascular event and/or,

d. Albuminuria and/or end-stage renal disease.

d. Diagnostic tests for COVID-19, for the patients and the surgical team:

I. Detailed clinical history on respiratory symptoms of the patient whose surgery was indicated and for all who have been in contact with him in the last 30 days is recommended.

II. The slightest suspicion of infection, primarily clinical, should be a reason for postponing the operation.

III. The use of diagnostic tests should follow the recommendations of the local institutions where the procedures will be performed.
IV. The same diagnostic recommendations apply to the surgical team.

e. Strategies to minimize the risks of patients during the waiting period ${ }^{12}$ :

I. For patients without adequate glycemic control with lifestyle changes and metformin, it is recommended to add glucagon peptide 1(GLP1) analogs and/or sodium-glucose co-transporter 2 (SGLT-2) inhibitors with the goal of glycemic control and weight loss/ maintenance.

- SGLT-2 inhibitors should not be used if COVID-19 is diagnosed due to an increased risk of ketoacidosis.

II. Reinforce the orientation of the use of low glycemic and/or hyper protein diets.

2. Recommendations for the perioperative period $^{13-15}$ :

a. Surgical team, including anesthesiologist:

I. In the scenario of community transmission, all healthcare workers are at risk of exposure to COVID-19, whether in the workplace or in the community.

II. The entire team should wear surgical masks in the hospital environment, including when examining the patient.

III. It is essential to reinforce hygiene measures directed to the surgical team, such as washing hands with soap and water ALWAYS before and after each contact with the patient; when touching the mask or the glasses etc.

IV. Before performing a surgical procedure, there must be available personal protective equipment (PPE) for the entire team

$V$. Strictly follow the recommendations of NT GVIMS/GGTES/ANVISA 04/2020 Recommendations for health services: prevention and control measures that should be adopted during care for suspected or confirmed cases of 
infection by the new coronavirus (SARS-COV-2) for the choice of PPE and safe dressing and undressing

- It is noteworthy that cloth masks are not PPE, and thus should not be used by the medical team during in the hospital.

VI. Any member of the surgical team, anesthetic, or hospital staff who presents "flu" symptoms (symptomatic) should be instructed not to participate in the operation, should be tested for COVID-19, and take a leave-of-absence, following the recommendations of the Ministry of Health.

VII.Stimulate simulations of dressing/ undressing for the whole team:

- Incorrect use of PPEs, regarding the model and how to dress it, should be avoided. Also, team contamination risk and improper PPE use may waste an already limited supply of equipment.

- It is essential to highlight that the moment of undressing is critical due to the risk of contamination, whether due to individual negligence and/or tiredness after a given surgical procedure.

VIII.It is essential to develop specific protocols and audits (minimally recommended, the Safe Surgery Protocol - Surgical Safety Checklist and another protocol for PPE's dressing/ undressing) to optimize workflow and prevent infections and other adverse events.

IX. Preferably, the surgical procedure should be performed by the most experienced/skilled surgeon to mitigate complications as well as decrease the surgical time.

$X$. It is essential to keep the smallest number of people within the operating area, especially inside the operating room. Thus, it is crucial to guide the support teams, limiting their permanence in the room, with the presence of those who are essential.

$X I$. Ratify the recommendations in regard to personal objects (purses, wallets, keys etc.) that should not be taken into the surgical area. In the case of cellular devices, their use should be very judicious, following the recommendations of the Hospital Infection Control Commission.

XII.During the patient's airway control for general anesthesia, the personnel in the room should be reduced. The surgical team should stay out until a definitive airway is established and the patient is connected to a closed anesthesia system.

XIII.A passive surveillance strategy should be implemented in the Hospital. Health professionals should be instructed to make a self-assessment of fever, cough, shortness of breath, or other non-specific symptoms, but suspicious of COVID-19. In the presence of any of these signs or symptoms, they should:

- Report this information to the Head of the health service;

- Receive immediate medical evaluation and follow-up actions;

- Leave-of-absence for up to 14 days.

XIV. Regarding the risks related to laparoscopic surgery versus the laparotomic approach, current scientific evidence is limited in patients with suspected or confirmed COVID-19. However, the virus has already been found in cells of the gastrointestinal tract and all fluids, including saliva, enteric content, feces, and blood ${ }^{15-17}$. Hence, it is suggested:

- To use disposable trocars mitigating the risk of leakage by valves and/or 
rubber membranes.

- In the case of permanent trocars, check the integrity of seals and reducers to minimize leakage during the procedure.

- To determine a single trocar to evacuate the smoke and pneumoperitoneum in a closed system and with filtering devices.

- To limit the incision to the diameter of the trocar to reduce the possibility of leakage at the port site.

$X V$. The decision whether or not to use the laparoscopic route should be individualized at the clinical and surgeon's discretion, taking into account the risk of contagion due to the technical issues inherent to the surgical instruments previously described.

$\mathrm{XVI}$. Although it is not the primary objective of this Technical Note, there is already a report on the findings of SARS-CoV-2 in the peritoneal fluid of active phase COVID-19 patients, further reinforcing the precautions described above ${ }^{18}$.

$X V I I$. The use of abdominal drainage should follow the surgeon's indication and should not be changed due to the pandemic.

XVIII. Patientsshould preferably beextubated, when possible, in the operating room, and if they require post-anesthetic recovery, it is advisable to undertake it in the operating room. In the case of patients requiring a longer stay in the post-anesthetic recovery unit, she/he should be transported with a mask and kept at a distance of not less than 1.5 meters from other patients.

XIX. The decision to transfer to the Intensive Care Unit is under the judgment of the surgical team in common agreement with the anesthesiologist, and should not be changed in the face of the pandemic. Thus, hospital resources that are being used to accommodate COVID-19 patients, such as the intensive care occupancy rate, should be reviewed.

b. Patient and companions:

I. It is essential to continuously train and encourage health professionals to be aware and early identify suspected cases of COVID-19 among patients, companions/visitors, and even among health care professionals.

II. One of the objectives of identifying suspected COVID-19 patients is to guide infection prevention and control strategies to prevent or limit transmission of the virus, especially within the Institution.

III. Screening and surveillance strategies should be established, and they can be widely adopted within health services.

IV. Keep health professionals trained and alert to:

- Case definitions (suspected or confirmed) of COVID-19;

- Clinical signs and symptoms of COVID-19;

- Relevant local epidemiology, including risk groups.

V. Require the test for COVID-19 in addition to a complete and duly signed free and informed consent form for all patients at the time of hospitalization.

VI. Patients and companions should be instructed to go to the hospital with a surgical mask, wash their hands as soon as they arrive, following with the use of gel-alcohol.

VII.Daily request health teams to report and discuss patients identified with symptoms/history compatible with COVID-19.

3. Recommendations for the postoperative period

I. The discharge criteria should be the 
same used outside the pandemic period. Everyone should be alert to symptoms suggestive of COVID-19, not only in the Hospital environment but also after discharge.

II. Hospital discharge, when very premature, may increase the risk of re-hospitalization. This may expose the patient to possible contagious environments to SARS-CoV-2, such as in the emergency care, taking into account the potential limited availability of beds.

III. Patients should be instructed for possible symptoms related to COVID-19 after discharge and, if present, they should contact the surgical team or the Hospital where the operation was performed.

IV. Nutrition is a critical determinant of the immune response. Considering that bariatric surgery leads to an anatomical rerouting of the gastrointestinal tract with potential for nutritional deficiencies, and that food intake is restricted in the immediate postoperative period, the question in regard to the need of dietary modification in the postoperative period of bariatric surgery is understandable.

- However, there is no evidence that additional supplementation, different from those already mentioned in the specific National and International guidelines for patients after bariatric surgery, changes the immune response. Attention should be given to clinical and laboratory evaluation of possible nutritional deficiencies ${ }^{19}$.

V. As there is the possibility of nutritional deficiencies of certain micronutrients in patients who are candidates for bariatric surgery, their investigation and correction are mandatory in the preoperative period.

VI. Gradual progression of the diet regarding the volume and the consistency according to tolerance is recommended. Therefore, it is essential to supplement, during the early postoperative period, a chewable multi-vitamin (or in drops), in addition to vitamin D3 and eventually injectable B complex.

VII. In addition to face-to-face care, it is suggested that if possible, the team provides remote nutritional assistance to patients in order to avoid any harm caused by malnutrition or hydration problems due to the potential inadequate dietary adaptation, in the postoperative period. That could lead patients to the need for intravenous replacement in a hospital environment or even a new hospitalization.

VIII.It is also suggested that the team provides remote telemedicine care to the patients, in this period of exception. The objective is to favor the early recognition of signs and symptoms related to COVID-19 disease, as well as to mitigate the possibility of contagion to patients in the outpatient and hospital settings.

- Psychological attention should be strengthened to patients in view of the possible negative biopsychosocial effects that the pandemic can determine to the general population and to the operated patients.

a. We also suggest that the teams provide psychological, face-to-face, and remote support, favoring safe care to the patients, at this time of the exception.

\section{DISCUSSION}

In Brazil, a country of continental dimensions, 
the COVID-19 distribution is uneven, as it is the viral infection peak. In this sense, public healthcare administrators have a fundamental role in the permanent evaluation of the geographical behavior of the dissemination of COVID-19. On the other hand, the pandemic has not prevented the natural evolution of conditions not related to the new coronavirus. In addition to cases of coronavirus infection, there are chronic diseases that have been plaguing the world for a long time with a high rate of morbidity and mortality, in particular obesity and T2D20.

Currently, $55.7 \%$ of the adult population in Brazil is overweight, and $19.8 \%$ is obese, according to the Surveillance of Risk and Protection Factors for Chronic Diseases Survey by Telephone Survey (VIGITEL MS), from $2018^{20}$. Vigitel data also show that $7.7 \%$ of the adult population has T2D and $24.7 \%$ hypertension diseases that have strong links with obesity. The National Health Survey (PNS) of 2013 indicates that, among adults with diabetes, $75.2 \%$ are overweight, and, among adults with hypertension, $74.4 \%$ are overweight. Thus, Brazil has reached the highest prevalence of obesity (19.8\%) in adults in the last thirteen years. Between 2006 and 2018 , the incidence increased by $67.8 \%{ }^{20}$.

According to the 16th Epidemiological Bulletin published by the Ministry of Health in 2019, T2D is the fourth leading cause of death in men and the third in women - the disease caused more than 48000 deaths, only in $2017^{21}$. It is also worth bearing in mind that T2D is a risk factor for death from heart attacks, stroke, and some types of cancer. The Brazilian Society of Cardiology (SBC) and the Society of Cardiology of the State of São Paulo (SOCESP) have raised awareness to a drop of up to $70 \%$ in cardiac procedures throughout the pandemic. Are patients failing to see their doctors? Or are they neglecting symptoms, afraid of going to the healthcare facilities?

An aggravating factor in this narrative is that people with T2D usually have high blood pressure and dyslipidemia. All are silent, yet potentially lethal especially when combined.

To make matters worse, the lack of control of these diseases, as well as of the blood glucose, can favor the most severe forms of COVID-1922.

Bariatric procedures remain a safe and effective intervention for high-risk patients with obesity. Clinical decision-making must be evidence-based in the context of the burden of chronic diseases. An interdisciplinary approach to the perioperative care is mandatory, with particular attention to nutritional and metabolic issues ${ }^{19}$.

During the pandemic, the delay in starting, or continuing the treatment of these patients can result in increased morbidity and mortality. The CFM's Technical Board of bariatric surgery, concerned with this situation, considers vital the prioritization based on the disease burden while resuming medical care. Many of the cases that the patient is not at a life-threatening emergency risk have increased morbidity and even mortality documented in different countries, which has led different surgical Societies to define structured recovery plans, such as the American College of Surgeons (ACS $)^{13}$.

Some patients with obesity and/or T2D have had their chances of successful treatment decreased by postponing the operations. Healthcare providers should also be concerned with this group, and consider planning treatment for these patients. Especially those patients whose treatment delays results in worse results, as this not only increases complications but also creates an even more significant burden to the health system.

Due to the progressive nature of obesity and diabetes, delayed surgery increases the risk of morbidity and mortality, requiring strategies to mitigate the damage. The risk of harm, however, varies among patients, depending on their risk stratification.

In Brazil, in the geographic regions where local governments have allowed the return to "normality", based on epidemiological data from COVID-19, elective operations have already been resumed, impending against a considerable accumulation of patients who would benefit from bariatric and metabolic surgery, during the quarantine period ${ }^{1,2}$.

So, how should we prioritize whom to serve first with limited resources?

On a broad level, the answer is simple. If patients are well enough to be safe surgical candidates, preference should be given to those with a higher risk of morbidity and mortality from their disease, if it is likely that this risk can be reduced by surgery.

Also, in many health systems, public or private, candidates for bariatric and metabolic surgery are 
currently placed on a single waiting list for elective surgery, regardless of their indication. The priority is established mostly on a first-come, first-served basis, rather than on the clinical need. This approach is comparable to placing all candidates for any surgical treatment. It should be clear that eligibility is not a synonym of prioritization.

\section{CONCLUSION}

Prioritizing elective operations should aim to facilitate access according to the clinical needs, in order to maximize access opportunity, and minimize the damage related to the delaying of the treatment. Previous categories of elective surgery were adapted to define a straightforward system of prioritization for bariatric and metabolic operations. These recommendations are based on evidences produced so far. Thus, they can be modified at any time, provided that new conclusive evidence is available or that the epidemiological situation of COVID-19 is altered in Brazil.

\title{
R E S U M O
}

\begin{abstract}
A priorização de qualquer operação eletiva visa facilitar o acesso do paciente de acordo com as necessidades clínicas, maximizando a equidade de acesso e minimizando os danos causados pelo atraso. As categorias de operações eletivas foram adaptadas para definir sistema de priorização objetiva que reflete esses princípios para operações bariátricas e metabólicas. Em razão dos fatores que contribuem para a morbidade e mortalidade da obesidade e do diabetes tipo 2, a priorização cirúrgica deve ser baseada na estratificação de risco clínico. Para pacientes com diabetes tipo 2, sugerimos que a operação possa ser priorizada para aqueles com maior risco de morbidade e mortalidade, em prazo relativamente curto. Da mesma forma, é necessário orientar a equipe cirúrgica quanto aos cuidados necessários tanto no pré, per e pós-operatório da cirurgia bariátrica e metabólica. As recomendações visam reduzir o risco de contágio hospitalar da equipe cirúrgica tanto entre profissionais de saúde quanto entre profissionais de saúde e pacientes. Em resumo, estas recomendações foram moldadas após análise minuciosa da literatura disponível e são extremamente importantes para mitigar os danos das complicações clínicas, sensíveis a doença obesidade e comorbidades, mantendo a segurança dos profissionais de saúde e dos pacientes.
\end{abstract}

Palavras chave: Cirurgia Bariátrica. Diabetes Mellitus Tipo 2. Obesidade. Comorbidade. Coronavirus. Pandemia.

\section{REFERENCES}

1. Conselho Federal de Medicina. Recomendação aos CRMs sobre avaliação dos atendimentos eletivos [Internet]; 2020 [cited 2020 May 27]. Available from: http://portal.cfm.org.br/images/stories/pdf/ recomendacao-cfm-atendimentos-eletivos.pdf.

2. ANVISA. Orientações para a prevenção e o controle das infecções pelo novo coronavírus (SARS-CoV-2) em procedimentos cirúrgicos - (complementar à nota técnica GVIMS/GGTES/ANVISA No 04/2020) [Internet]; 2020 [upadate 2020 May 25; cited 2020 May 27]. Available from: http://portal.anvisa.gov. br/documents/33852/271858/Nota+técnica+062020+GVIMS-GGTES-ANVISA/40edaf7d-8f4f48c9-b876-bee0090d97ae.

3. Adams TD, Davidson LE, Litwin SE, Kim J, Kolotkin $\mathrm{RL}$, Nanjee $\mathrm{MN}$, et al. Weight and metabolic outcomes 12 years after gastric bypass. N Engl J Med. 2017;377(12):1143-55.
4. Maciejewski ML, Arterburn DE, Van Scoyoc L, Smith VA, Yancy WS Jr, Weidenbacher HJ, et al. Bariatric surgery and long-term durability of weight loss. JAMA Surg. 2016; 151(11):1046-55.

5. Schauer PR, Bhatt DL, Kirwan JP, Wolski K, Aminian A, Brethauer SA, et al. Bariatric surgery versus intensive medical therapy for diabetes - 5-year outcomes. N Engl J Med. 2017;376(7):641-51.

6. O'Brien R, Johnson E, Haneuse S, Coleman KJ, O'Connor PJ, Fisher DP, et al. Microvascular outcomes in patients with diabetes after bariatric surgery versus usual care. Ann Intern Med. 2018;169(5):300-10.

7. Ikramuddin S, Korner J, Lee WJ, Thomas AJ, Connett JE, Bantle JP, et al. Lifestyle intervention and medical management with vs without Rouxen-Y Gastric Bypass and control of hemoglobin A1C, LDL cholesterol, and systolic blood pressure at 5 Years in the Diabetes Surgery Study. JAMA. 2018;319(3):266-78. 
8. Mingrone G, Panunzi S, De Gaetano A, Guidone C, laconelli A, Nanni G, et al. Bariatric-metabolic Surgery Versus Conventional Medical Treatment in Obese Patients With Type 2 Diabetes: 5 Year FollowUp of an Open-Label, Single-Centre, Randomised Controlled Trial. Lancet. 2015;386(9997):964-73.

9. Simonson DC, Halperin F, Foster K, Vernon A, Goldfine AB. Clinical and Patient-Centered Outcomes in Obese Type 2 Diabetes Patients 3 Years After Randomization to Roux-en-Y Gastric Bypass Surgery Versus Intensive Lifestyle Management: The SLIMM-T2D Study. Diabetes Care. 2018;41(4):670-9.

10. Conselho Federal de Medicina. Recomendação CFM n 1/2020 de, 21 de maio de 2020. Dispõe sobre a realização de cirurgias eletivas bariátricas e metabólicas no período de pandemia da COVID-19 [Internet]; 2020 [cited 2020 May 26]. Available from: https://sistemas.cfm.org.br/normas/ visualizar/recomendacoes/BR/2020/1.

11. Rubino F, Cohen RV, Mingrone G, le Roux CW, Mechanick JI, Arterburn DE, et al. Bariatric and metabolic surgery during and after the COVID-19 pandemic: DSS recommendations for management of surgical candidates and postoperative patients and prioritisation of access to surgery. Lancet Diabetes Endocrinol. 2020 May 7. doi:10.1016/ S2213-8587(20)30157-1.

12. Bornstein SR, Rubino F, Khunti K, Mingrone G, Hopkins D, Birkenfeld AL, et al. Practical recommendations for the management of diabetes in patients with COVID-19. Lancet Diabetes Endocrinol. 2020;8(6):546-50.

13. American College of Surgeons. Considerations for optimum surgeon protection before, during, and after operation [Internet]; 2020 [cited 2020 May 27]. Available from: https://www.facs.org/ covid-19/clinical-guidance/surgeon-protection.

14. Correia MITD, Ramos RF, Bahten LCV. The surgeons and the COVID-19 pandemic. Rev Col Bras Cir. 2020;47:e20202536.

15. To KK, Tsang OT, Leung W, Tam AR, Wu T, Lung $D C$, et al. Temporal profiles of viral load in posterior oropharyngeal saliva samples and serum antibody responses during infection by SARS-COV-2: an observational cohort study. Lancet Infect Dis. 2020; 20(5):565-74.

16. Lescure FX, Bouadma L, Nguyen D, Parisey M, Wicky $\mathrm{PH}$, Behillil $\mathrm{S}$, et al. Clinical and virological data of the first cases of COVID-19 in Europe: a case series. Lancet Infect Dis. 2020;20(6):697-706.

17. Ramos RF, Lima DL, Benevenuto DS. The Brazilian College of Surgeons recommendations regarding laparoscopic surgery response to the COVID-19 pandemic. Rev Col Bras Cir. 2020;47:e20202570.

18. Coccolini F, Tartaglia D, Puglisi A, Giordano C, Pistello $M$, Lodato $M$, et al. SARS-CoV-2 is present in peritoneal fluid in COVD-19 patients. Ann Surg. 2020 [Internet].Epub Ahead of Print [cited 2020 May]. Available from: https://journals.Iww.com/ annalsofsurgery/Documents/SARS-CoV-2\%20 is $\% 20$ present $\% 20$ in $\% 20$ peritoneal\%20fluid $\% 20$ in\%20COVID-19\%20patients.pdf.

19. Mechanick JI, Youdim A, Jone DB, Garvey WT, Hurley DL, McMahon MM, et al. Clinical Practice Guidelines for the Perioperative Nutritional, Metabolic, and Nonsurgical Support of the Bariatric Surgery patient--2013 Update: Cosponsored by American Association of Clinical Endocrinologists, The Obesity Society, and American Society for Metabolic \& Bariatric Surgery. Obesity (Silver Spring). 2013;21:Suppl 1(0 1):S1-27.

20. Ministério da Saúde(BR). VIGITEL BRASIL 2018 [Internet]; 2018 [cited 2020 May 26]. Available from: https://portalarquivos2.saude.gov.br/images/ pdf/2019/julho/25/vigitel-brasil-2018.pdf.

21. Araújo VEM, Vasconcelos $C H$, Lecca RCR, França GVA, Macário EM. Perfil de Mortalidade. Bol Epidemiol [Internet]. 2019 set [2020 May 10]; 50(n. esp.):115-7. (Número especial: Vigilância em Saúde no Brasil 2003|2019). Available from: https://www. saude.gov.br/images/pdf/2019/dezembro/05/ Boletim-Epidemiologico-Especial-SVS-16-anosweb.pdf.

22. Ministério da Saúde(BR). Secretaria de Vigilância em Saúde. Boletim Epidemiológico Especial [Online]; 2020 [cited 2020 May 26]. Available from: https:// portalarquivos.saude.gov.br/images/pdf/2020/ May/21/2020-05-19---BEE16---Boletim-do-COE13h.pdf 
Recebido em: 27/05/2020

Aceito para publicação em: 03/06/2020

Conflito de interesses: não.

Fonte de financiamento: nenhuma.

\section{Endereço para correspondência:}

Leonardo Emilio da Silva

E-mail: leoemilio01@gmail.com/leoemilio01@gmail.com

(c) (i) 